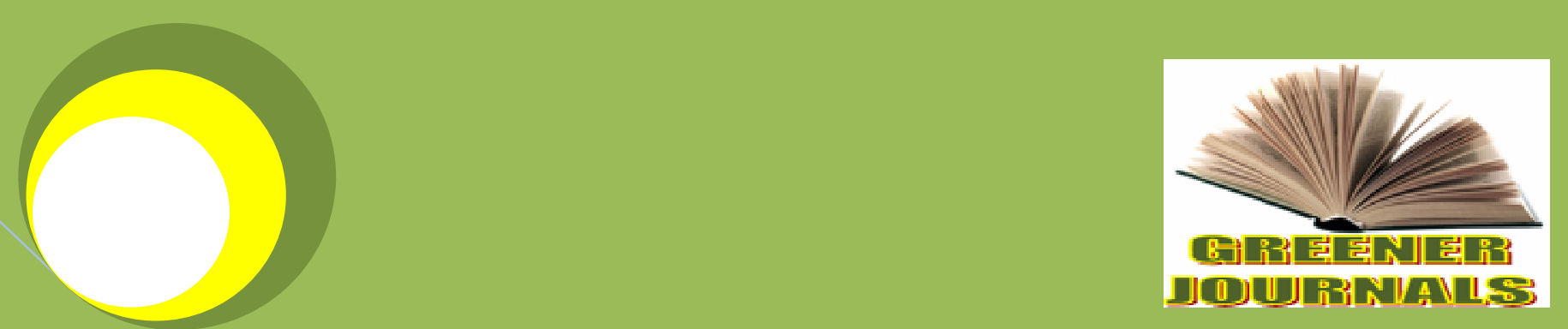

Greenerilournal of Plant Breedingand Crop science

ISSN: 2354-2292

Submitted: 19/04/2016

Accepted: 06/05/2016

Published: 31/05/2016,

DOI: http://doi.org/10.15580/GJPBCS.2016.3.050316082

Genotype * Environment Interaction for Grain Yield of Some Field pea Genotypes in Central and North Eastern Zones of South Region,
Ethiopia

By

Ersullo LJ 


\title{
Genotype $\times$ Environment Interaction for Grain Yield of Some Field pea Genotypes in Central and North Eastern Zones of South Region, Ethiopia
}

\author{
Ersullo LJ \\ Crop Research Process, Hawassa Agricultural Research Center, South Agricultural Research Institute, \\ P.O.Box 6, Hawassa, Ethiopia. \\ Email: ersulo33 @gmail.com
}

\begin{abstract}
Plant breeders invariably encounter GE interactions when testing varieties across a number of environments. The objective of this study was to identify the stability of grain yield of fifteen field pea genotypes by determining GE interaction effects obtained by AMMI analysis and to select genotypes with better performances depending on the differential genotypic responses to environments. The study was carried out for two consecutive years (2011 - 2012) at three locations and for one year at three additional locations in 2012 (a total of 9 environments) in 5 administrative zones of South Nations, Nationalities and Peoples Region, Ethiopia. The experiment was laid out in randomized complete block design with three replications. To determine the effects of GE interaction on yields, the data were subjected to Additive Main effects and Multiplicative Interaction (AMMI) analysis using GenStat $15^{\text {th }}$ ed. The result of combined analysis of variance for grain yield of 15 field pea genotypes tested across 9 environments showed that there is highly significant difference among the environments, genotypes and GE interaction with the contribution of $75.10,7.95$ and $16.94 \%$ sum of squares, respectively. The mean grain yield of the genotypes across the environments ranged from $1937.2 \mathrm{~kg} / \mathrm{ha}$ for genotype G8 to $2755.3 \mathrm{~kg} / \mathrm{ha}$ for G7, with a grand mean yield of $2248.2 \mathrm{~kg} / \mathrm{ha}$. The two best performing genotypes; G15 and G7 with relatively larger absolute IPCA-1 scores were found to have specific adaptations to some environments such as E1 and E7. According to yield stability index (YSI), the most desirable genotypes which can be considered as relatively adapted to wider environments and with grain yield above the grand mean were G4 and G2.
\end{abstract}

Key words: field pea genotypes, grain yield, G x E interaction, AMMI model, analysis of variance.

\section{INTRODUCTION}

$G \times E$ interaction is an important feature of crop improvement that should be considered in a breeding program aimed at developing crop varieties for multi-environments and help in identifying varieties that have either specific or general adaptation which can be exploited for varietal recommendation (Fekadu et al., 2012; Bose et al., 2014). The stability of a cultivar refers to its consistency in performance across environments and is affected by the presence of GE interactions. The significance exhibited by GE interaction indicates that each genotype interacted differently at each location (Anandan et al., 2009). In the presence of significant GE interactions, stability parameters are estimated to determine the superiority of individual genotypes across the range of environments (Riazet al., 2013). Genotypes that provide high average yields with minimum GE interaction have been gaining importance over increased yields. Plant breeders invariably encounter GE interactions when testing varieties across a number of environments. In order to meet up the demand, development of high yielding genotypes with desirable agronomic traits for diverse ecosystem is therefore a necessity (Ogunbayo et al., 2014).

Several methods of estimating phenotypic stability across environments by determining GE interaction effects are available (Eberhart and Russel, 1966; Crossa, 1990). However, AMMI model has been revealed to be more efficient because it captures a large portion of the GE interaction sum of squares and austerely separates main and interaction effects that present agricultural researchers with different kinds of opportunities, and this model often provides agronomically meaningful interpretation of the data (Ebdon and Gauch, 2002; Bose et al., 2014).

According to Romagosa and Fox, (1993); Kaya et al., (2002); Nassir and Ariyo (2011) AMMI model provides a hybrid analysis that incorporates both the additive and multiplicative components of the two-way data structure and is powerful in revealing a scale for principal component analysis (PCA) scores which allows estimation of specific GE interaction terms. Depending upon the magnitude of the interactions or the differential genotypic responses to 
environments; the varietal rankings can differ greatly across environments. Assessing any variety or agronomic treatment without including its interaction with the environment is incomplete and thus limits the accuracy of yield estimates (Crossa et al., 1991).

The objective of this study was to identify the stability of grain yield of fifteen field pea genotypes by determining GE interaction effects obtained by AMMI analysis and to select genotypes with better performances depending on the differential genotypic responses to environments.

\section{MATERIALS AND METHODS}

\section{Description of test genotypes and environments}

A total of fifteen field pea genotypes were evaluated at six locations in 5 administrative zones (Kokate in Wolaita, $\mathrm{H} /$ Selam and Bona in Sidama, Bule in Gedeo, Alichi-Weriro in Silte and Bobicho in Hadiya zone) of the South Nations, Nationalities and Peoples Region (SNNPR), Ethiopia. The trial was conducted under rain-fed condition for two consecutive years (2011and 2012) at three locations (Kokate, Bule and Alicho-Weriro) and for one year at three additional locations (H/selam, Bona and Bobicho) in 2012 totalling nine environments (Table 1). Fetien and Bjornstad, (2009); Sabaghniaet al., (2013; Fisehaet al., 2015) also studied GE interaction of food barley, durum wheat and sesame genotypes, respectively, using additional locations after the first and the second seasons.

In the present study, the genotypes comprised of fourteen released varieties viz. Tullu-Dimtu (G1), Bariso (G3), Tegegnech (G4), Agrit (G5), Latu (G6), Megeri (G7), Gume (G8), Arjo-1 (G9), Senk (G10), Wolmera (G11), Weyitu (G12), Ambericho (G13), URJI (G14) and Burkitu (G15), that were released through different agricultural research centers of the country including one Farmers' cultivar (G2) as a local check. In each environment, the experimental design was a Randomized Complete Block Design (RCBD) with three replications. A plot consisted of 6 rows of a genotype and each row was $5 \mathrm{~m}$ long comprising a plot size of $6 \mathrm{~m}^{2}(1.2 \times 5 \mathrm{~m})$. The rows were $0.2 \mathrm{~m}$ apart while plant-to-plant distance in each row was $0.05 \mathrm{~m}$. Fertilizer was applied as basal application during planting in the form of diammonium phosphate (DAP) at the rate of 18 and $46 \mathrm{~kg} / \mathrm{ha} \mathrm{N}$ and $\mathrm{P}_{2} \mathrm{O}_{5}$, respectively. The gangways which were left between plots and blocks were 1.5 and $2 \mathrm{~m}$, respectively. Weeds were controlled manually as at when due.

Table 1: Description of the experimental sites

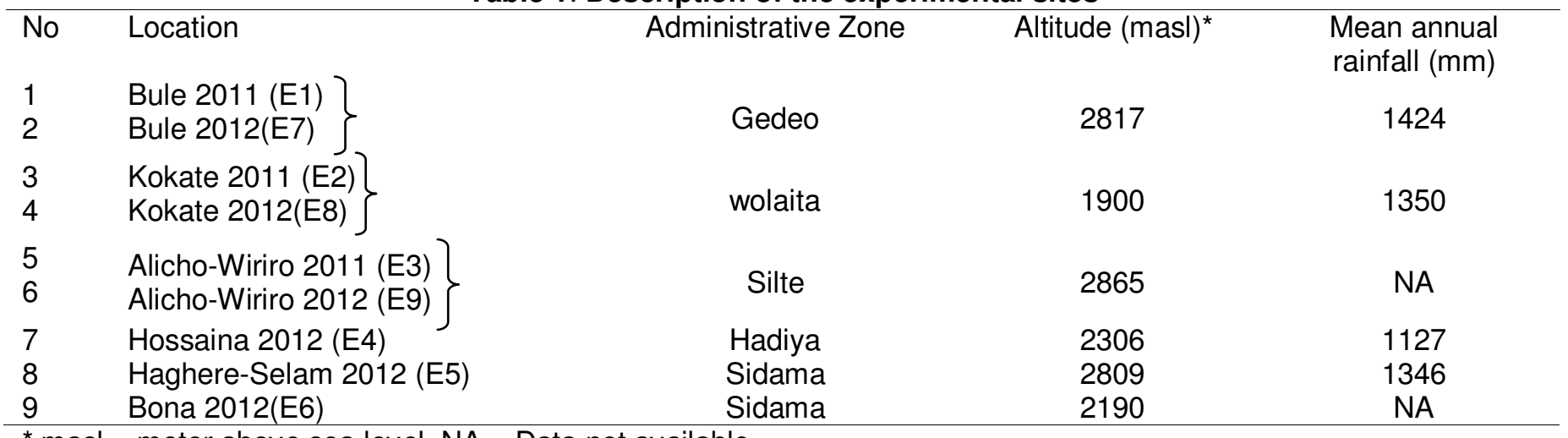

${ }^{*}$ masl $=$ meter above sea level, NA = Data not available

Source: National Meteorological Agency, Hawassa Branch Directorate and Worabe Agricultural Research Center

\section{Statistical analysis}

The mean grain yield performances of the genotypes and environments, the significance level of variations and mean separation of grain yield were done (Table 3) using SAS software version 9.0, whereas the AMMI analyses were subjected to GenStat version 15. Mean separation was done using the Duncan's Multiple Range Test (DMRT). Analysis of variance was used to partition variance into three components: genotypic, environmental and GE interaction deviations from the grand mean. Subsequently, multiplication effect analysis is used to partition GE deviations into different interaction principal component axes (IPCA), which can be tested for statistical significance through ANOVA (Odewaleet al., 2013). The AMMI model method was employed to investigate the grain yield response of the genotypes to different environments. 
The AMMI model 1 biplotwas generated from main effects of genotypes, environments and the IPCA 1 scores. The biplot was drawn by placing the overall mean on the X-axis and respective score (IPCA1) on Y-axis. The AMMI analysis first fits additive effects for genotypes and environments by the usual additive analysis of variance procedure and then fits multiplicative effects for GE interaction by principal component analysis (PCA). The AMMI model equation following Zobelet al., (1988) is:

$$
Y i j=\mu+\mathrm{G} i+E j+{ }^{\mathrm{n}} \Sigma \lambda_{\mathrm{k}} a_{\mathrm{ik}} Y_{\mathrm{jk}}+\epsilon_{i j}
$$

Where, Yijis the yield of the $i^{\text {th }}$ genotype in the $j^{\text {th }}$ environment; $\mu$ is the grand mean; Gi and Ej are the genotype and the environment deviations from the grand mean, respectively; $\lambda_{k}$ is the eigenvalue of the PCA axis k; $\alpha_{i k}$ and $\gamma_{j k}$ are the genotype and environment principal component scores for axis $k ; n$ is the number of PCA axes considered and $\epsilon i j$ is the residual term which includes the experimental error.

The additive part of the AMMI model ( $\mu, \mathrm{Gi}$ and $\mathrm{Ei})$ was estimated from an analysis of variance and the multiplicative part $\left(\lambda_{k}, a_{i k}\right.$, and $\left.\gamma_{j k}\right)$ was from a principal component analysis. The interaction between any genotype and environment was estimated by multiplying the score for the interaction principal component axis (IPCA) of a genotype by an environment IPCA score (Van et al., 1993). The greater the IPCA (Interaction Principal Component Axis) scores, either negative or positive, indicated the specific adaptation of a genotype to certain environments.

The AMMI model 1 biplot was generated from the main effect and first multiplicative axis term (IPCA-I) of both genotypes and environments. The abscissa shows the main effects and the ordinate shows the IPCA1 scores that capture interaction effects. The greater the IPCA scores, either negative or positive, the more specifically adapted a genotype to certain environment. The more the IPCA scores tend towards zero, the more stable the genotype is over all the environments (Crossa, 1990; Kumar et al., 2011; Bose et al., 2014; Dewiet al. 2014). Genotypes or environments appearing almost on a perpendicular line have similar means and those falling almost on a horizontal line have similar interaction patterns.

\section{AMMI stability value (ASV)}

The AMMI's stability value (ASV) was calculated as follows based on the suggestion of Purchase (1997).

$\mathrm{ASV}=\sqrt{[(\text { SSpca } 1 / \text { SSpca })(\text { Gpca1 score })]^{2}+(\text { Gpca2 score })^{2}}$

Where SSpca1/SSpca2 is the weight given to the IPCA-value by dividing the IPCA1 sum of squares by the IPCA2 sum of squares.

GPCA1 score $=$ PCA1 score for that specific genotype, and

GPCA2 $=$ PCA 2 score for that specific genotype.

In ASV method, genotypes with least ASV scores are the most stable across environments (Purchase et al., 2000; Odewale et al., 2013; Bose et al., 2014).

\section{Yield stability index (YSI):}

The YSI was computed by the following formula as suggested by Bose et al., (2014):

$\mathrm{YSI}=\mathrm{RASV}+\mathrm{RY}$

where, RASV is the rank of AMMI stability value and RY is the rank of mean grain yield of genotypes across environments. YSI incorporates both mean yield and stability in a single criterion. Low values of the parameter show desirable genotypes with high mean yield and stability.

\section{RESULTS AND DISCUSSION}

The mean grain yields of the genotypes across the environments ranged from $1937.2 \mathrm{~kg} / \mathrm{ha}$ for genotype G8 to $2755.3 \mathrm{~kg} / \mathrm{ha}$ for G7, followed by G15 with mean grain yield of $2624.1 \mathrm{~kg} / \mathrm{ha}$ (Table 3). Reversely, except five genotypes; viz. G7, G15. G4, G2 and G5, all the remaining ten genotypes performed below the grand mean in their grain yield. 


\section{Combined AMMI Analyses of Variance}

The result of combined analysis of variance for grain yield of 15 field pea genotypes tested across 9 environments showed that there is a highly significant difference among the environments, genotypes and GE interaction with the contribution of $75.10,7.95$ and $16.94 \%$ of the treatment sum of squares, respectively (Table 2). Similarly, Acikgozet al., (2009); Habtamuand Million, (2013); Tamene et al., (2013; Yayis et al., (2014) reported significantly different responses of environments, genotypes and GE interaction in grain yields of field pea genotypes. There are also many other studies on other crops that showed significant differences of $\mathrm{G} \times \mathrm{E}$ interactions. Accordingly, Fetien and Bjornstad, (2009) on barley Ersullo et al., (2013) on linseed Odewale et al., (2013) on coconut and Riaza et al., (2013) on cotton genotypes reported significant differences among the environments, genotypes and GE interactions.

In this study, the large environmental sum of squares indicated that environments were diverse, with large differences among environmental means causing most of the variation in grain yield. The magnitude of the GE interaction sum of squares was more than twice larger than that of genotypes, indicating that there were differences in genotypic responses across the environments. The significant and relatively large percentage of the total variation attributable to $G \times E$ interaction suggests that genotypes responded differentially to environments (Dewi, et al., 2014).

GE interaction was further partitioned by principal component analysis. It is evident that at least 4 axes must be retained for explaining stability or using the proposed simultaneous selection indices (Farshadfar and Sutka, 2006; Hassan et al., 2012). Correspondingly, the stability values were calculated by retaining 4 PCA axes in the model (AMMI1-AMMI4). Consequently, the results of AMMI analysis indicated that the first three IPCA scores were found to be highly significant at $P \leq 0.001$ explaining $39.55,20.36$, and $19.20 \%$ of GE interaction sum of squares, respectively (Table 2). However, since the magnitudes of the first two PCs are relatively high which accounted for a total of $59.91 \%$ of the interaction variation with $35.7 \%$ for the corresponding degrees of freedom, the most information could be gained in these two axes. According to Zobel et al., (1988); Gauch and Zobel, (1996); Yan and Rajcan, (2002); Sabaghnia et al., (2013), the most accurate model for AMMI can be predicted by using the first two PCAs. Thus the interaction of this study was best predicted by the first two principal components of GE interaction.

\section{AMMI biplot analysis}

The AMMI model 1 biplot of the trials is demonstrated in Figure 1. The graph space is divided into 4 quadrants from low yielding environments in quadrants I and IV to high yielding in quadrants II and III. When a genotype and environment have the same sign on the IPCA axis, their interaction is positive and if different, their interaction is negative (Kumar et al., 2011; Makinde and Ariyo, 2011; Alake and Ariyo, 2012). Genotypes and environments with IPCA 1 scores tending towards zero, have small interaction effects and considered stable, while genotypes and environments with large IPCA 1 scores, either positive or negative direction were highly interactive (Crossaet al., 1991;Gauch, 2006; Anandanet al., 2009; Mukherjee et al., 2013; Tameneet al., 2013; Bose et al., 2014).

In the present study, AMMI adjusted mean grain yield, IPCA 1 and 2 scores, AMMI stability values (ASV) and ranking orders of 15 field pea varieties tested at 9 environments are presented in (Table 4). The first AMMI biplot accounted for $89.75 \%$ of the treatment sum of squares of which $75.10 \%$ was attributed due to the environments, $7.95 \%$ due to the genotypes and $6.70 \%$ was due to the IPCA1 score. The remaining multiplicative interaction principal component which is not included in AMMI model 1 biplot analysis (IPCA2 - IPCA4 and the residuals) accounted only for $10.24 \%$ of the treatment sum of squares (Table 2 ).

The highest negative IPCA-I score (-27.0536), was observed for the lowest yielding genotype G8 and it was positively interacted with low potential environments viz., E8, E6 and E2 (Fig.1 and Table 4). As presented in Table 5, this genotype (G8) was also recommended by the first four AMMI selections for only these three low yielding environments. The top 4 high yielding genotypes G15, G7, G4 and G2 with positive IPCA-I scores 26.30, 12.39, 5.70 and 2.82 respectively, were positioned in quadrant II; the latter two showing relatively better stability to the test environments than the former ones.

The two best performing genotypes; G15 and G7 with relatively larger absolute IPCA-1 scores were found to have specific adaptations to some environments such as E1 and E7. Whatever the direction is, the greater the IPCA scores, the more specifically adapted these genotypes are to certain environments (Crossaet al., 1990). The genotypes G13, G3 and G6 with IPCA1 scores closest to zero showed lesser differential response to the changes in the testing environments as compared to the other genotypes indicating that they can be considered as stable genotypes. However, they performed below the grand mean in their grain yield.

One of the genotypes, G5, with grain yield potential of a little above the grand mean and with IPCA1 score 11.37 was seen in quadrant III being well adapted to high potential environments (E3, E4 and E9). Other genotypes such as G1, G9, G10, G11, G12 and G14 showed reasonably better stability performance across a range of environments, but they performed lower than the grand mean in their mean grain yield. 
As indicated in Fig. 1, high potential environments; E9, E4 and E3 were sparsely distributed in quadrant III with minimum interaction effects, while the lower potential environments; E2, E6, and E8 were sparsely distributed in quadrant IV with relatively high negative interaction values.Odewaleat al., (2013)also reported the lowest yielding environments with the highest negative interaction IPCA1scores. E5 and E7 were distributed in quadrant I with mean yield potentials below the grand mean.

One of the low yielding environments, E1 (Bule 2011), is not posed in the figure because it was outlier due to its highest positive IPCA I (36.80) score indicating that it was highly unstable and a non-suitable environment for most of the genotypes under the study. However, on the same location (Bule), in 2012, the IPCA1 score remarkably lowered to 13.43. On the contrary, the location Alicho-Wiriro in 2011 with the least IPCA1 score -2.96 (closest to zero) was considered as the most favorable location for almost all the genotypes under the test. But, in 2012 this score was displaced away from zero to 9.86 indicating that some genotypes interacted with this particular environment. This clearly suggested that, stability tests of genotypes and locations need two or more seasons instead of a single season (Debeloet al., 2004; Anandanet al., 2009).

According to the first four AMMI selections of genotypes for the testing environments (Table 5), the highest yielding genotype G7 was recommended for 8 environments followed by G4 and G15 for 6 and 5 environments, respectively. The AMMI selection also indicated (recommended) that genotype G6 for environment E7, genotypes G11 and G3 for E9, genotype G10 for E1 and E2, and genotype G14 for E2 and E9. Ersulloet al., (2013) also reported the first four genotypes of AMMI selections for oil yield of linseed varieties per environment.

Plot of Gen \&Env IPCA 1 scores versus means

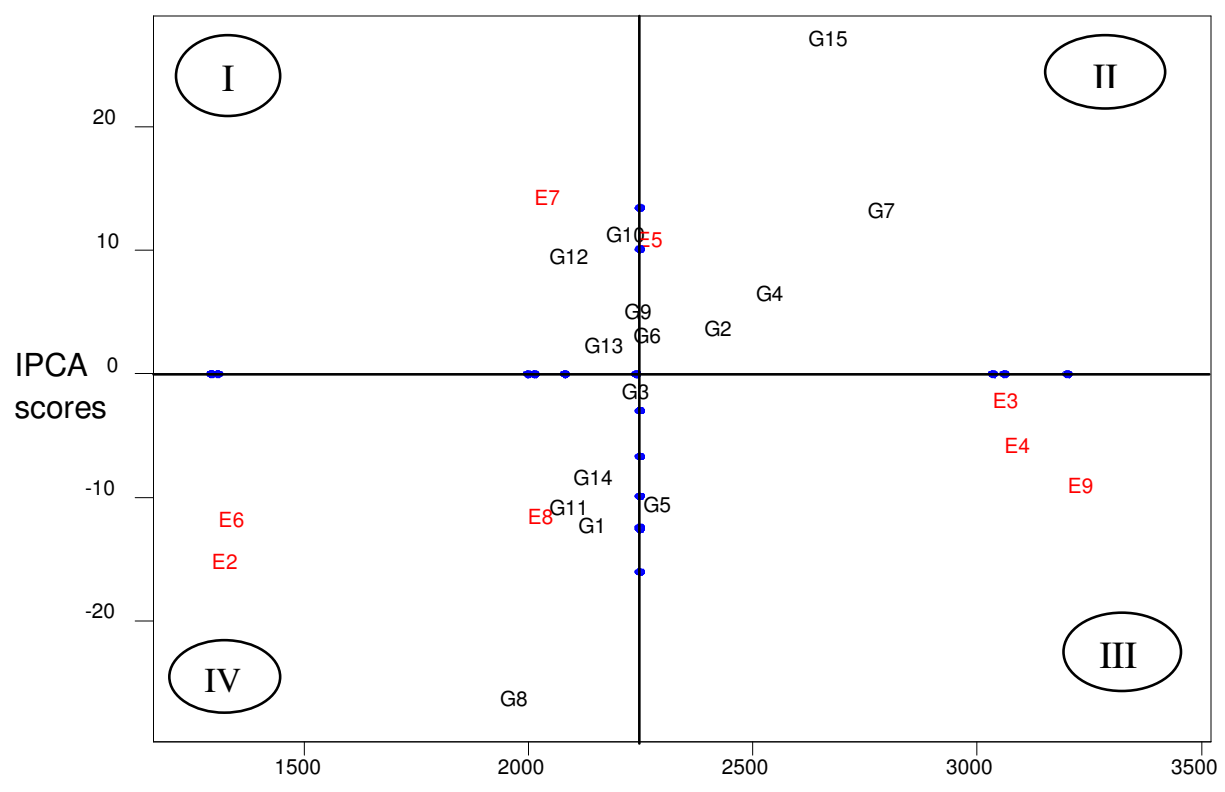

Genotype \& Environment means

Figure 1. The AMMI model I biplot of field pea grain yield of fifteen genotypes evaluated in nine environments

Genotypes:- G1= Tulu-Dimtu, G2=Farmers' cultivar, G3= Bariso, G4 = Tegegnech, G5= Agrit, G6= Latu, G7= Megeri, G8= Gume, G9= Arjo-1, G10= Seenk, G11= Wolmera, G12= Weyitu, G13= Ambericho, G14= Urji and G15= Burkitu

Environments:- E1= Bule 2011, E2= Kokate 2011, E3= Alicho-Wiriro 2011, E4= Hossaina 2012, E5= Haghere-Selam 2012, E6= Bona 2012, E7= Bule 2012, E8= Kokate 2012 and E9= Alicho-Wiriro 2012 


\section{AMMI stability value (ASV) and Yield stability index (YSI)}

AMMI stability value (ASV) is comparable with the methods used by Shukla, Eberhart, and Russell for genotype stability (Purchase et al., 2000). This quantitative stability value is used to rank genotypes through the AMMI model showing that in ASV method, genotypes with least ASV scores are the most stable. As cited by Bose et al., (2014), Mohammadiet al., (2007) and Mohammadi and Amri, (2008) exhibited that stability per se should however not be the only selection parameter because the most stable genotypes would not necessarily give the best yield performance, hence, there is a need for approaches that incorporate both mean yield and stability in a single index.

The rank of ASV and yield mean in such a way that the lowest ASV takes the rank one, while the highest yield mean takes the rank one (Alake and Ariyo, 2012; Bose et al., 2014) and then the ranks are summed in a single simultaneous selection index of yield and yield stability named as: yield stability index (YSI). The least YSI is considered as the most stable with high grain yield. Hassan et al., (2012) also indicated that both yield and stability of performance should be considered simultaneously to exploit the useful effect of GE interaction and to make selection of the genotypes more precise and refined.

In the present study, Table 4 shows mean grain yield, the AMMI model IPCA1 and IPCA2 scores, the AMMI stability value (ASV) and yield stability index (YSI) of each genotype and environment. According to ASV ranking, genotypes G13, G6, G9, G4 and G2 (in their ranking order) were among genotypes with lower ASV values indicating that they are relatively stable genotypes. Yield stability index (YSI) also revealed that these five genotypes were relatively stable with the change of ranks; G4 being the most stable with third rank in grain yield performance followed by G6, G2, G9 and G13. However, among these five genotypes, except G4 and G2 the remaining three genotypes performed below the grand mean in their grain yield.

Therefore, according to the YSI method, the most desirable genotypes which can be considered as widely adapted and with grain yield above the grand mean were G4 and G2 followed by G7 which ranked first in mean grain yield among the 15 genotypes under the test (Table 4 ).

Table 2: Additive main effects and multiplicative interaction (AMMI) analysis of variance for grain yield of 15 field pea varieties combined at 9 environments

\begin{tabular}{|c|c|c|c|c|c|c|}
\hline Sources & Df & SS & MS & \%Trt SS & $\begin{array}{c}\text { \%Trt SS of } \\
\text { GE }\end{array}$ & $\%$ GE SS \\
\hline Treatments & 134 & 247465336 & $1846756^{\star \star \star}$ & & & \\
\hline Gentype (G) & 14 & 19680059 & $1405719^{* \star *}$ & 7.95 & & \\
\hline Environments (E) & 8 & 185857431 & $23232179^{* * *}$ & 75.10 & & \\
\hline Interaction (GE) & 112 & 41927846 & $374356^{\star * *}$ & 16.94 & & \\
\hline IPCA 1 & 21 & 16583109 & $789672^{\star \star *}$ & & 6.70 & 39.55 \\
\hline IPCA 2 & 19 & 8538080 & $449373^{\star * *}$ & & 3.45 & 20.37 \\
\hline IPCA 3 & 17 & 8050021 & $473531^{* * *}$ & & 3.25 & 19.20 \\
\hline IPCA 4 & 15 & 4021813 & $268121 n s$ & & 1.63 & 9.59 \\
\hline Residuals & 40 & 4734823 & 118371 & & 1.91 & 11.29 \\
\hline Error & 252 & 40397443 & 160307 & & & --- \\
\hline
\end{tabular}


Table 3 Grain yield performance of 15 field pea genotypes at 9 environments

\begin{tabular}{|c|c|c|c|c|c|c|c|c|c|c|c|c|}
\hline \multicolumn{2}{|c|}{ Gen/Env code } & E1 & E2 & E3 & E4 & E5 & E6 & E7 & E8 & E9 & $\begin{array}{l}\text { Genotypic } \\
\text { Mean }\end{array}$ & $\begin{array}{l}\text { ran } \\
\mathrm{k}\end{array}$ \\
\hline \multicolumn{2}{|c|}{ G6 } & 1913.3cd & $1046.8 \mathrm{bc}$ & 2957.6abc & 2923.2bcd & 2453.6abcd & 1333.1abc & 2313.8abcd & 1835.8abc & $3321.4 a b c$ & 2233.2cdef & 6 \\
\hline \multirow{2}{*}{\multicolumn{2}{|c|}{$\begin{array}{l}\text { G15 } \\
\text { G5 }\end{array}$}} & $3707.1 \mathrm{a}$ & 1270.2abc & 3516.3ab & 3428.2ab & 2970.7ab & 1651.4abc & 2087.3bcd & 2268.9ab & $2716.5 \mathrm{bc}$ & 2624.1ab & 2 \\
\hline & & $1464.6 \mathrm{~cd}$ & $1642.3 a$ & 2898.8abc & $2764.2 \mathrm{bcd}$ & 2503.6abc & 1668.2ab & $2150.1 \mathrm{abcd}$ & $2302.2 a$ & 2903.6abc & 2255.3cde & 5 \\
\hline \multicolumn{2}{|c|}{ G10 } & $2434.3 b c$ & 1347.2abc & $2890.1 \mathrm{abc}$ & $2373.4 d$ & 2417.7abcd & $914.8 c$ & 2019.0bcd & 1934.7abc & $3210.2 \mathrm{abc}$ & 2171.3def & 9 \\
\hline \multicolumn{2}{|c|}{ G13 } & $2097.6 b c$ & 1372.1abc & $2611.2 \mathrm{c}$ & $2956.4 \mathrm{bcd}$ & 2098.3bcd & $1020.3 b c$ & $1898.0 \mathrm{~d}$ & 1830.3 & $3235.4 a b c$ & 2124.4def & 10 \\
\hline \multicolumn{2}{|c|}{ G14 } & $1679.1 \mathrm{~cd}$ & 1352.8abc & 3107.0abc & $2810.4 \mathrm{bcd}$ & $1793.8 \mathrm{~cd}$ & $956.1 \mathrm{bc}$ & 1695.8de & 2006.0abc & 3493.5abc & 2099.4def & 12 \\
\hline \multicolumn{2}{|c|}{ G8 } & $921.2 d$ & 1545.0ab & $2758.7 \mathrm{c}$ & $2900.7 \mathrm{bcd}$ & $1977.3 \mathrm{~cd}$ & $1862.6 a$ & 882.0f & 2011.1abc & $2576.4 \mathrm{c}$ & $1937.2 \mathrm{f}$ & 15 \\
\hline \multicolumn{2}{|c|}{ G7 } & 3008.3ab & 1404.8abc & $3100.7 \mathrm{abc}$ & $3716.2 \mathrm{a}$ & $3054.2 a$ & $1926.7 a$ & 2659.0abc & 2243.9ab & $3684.2 \mathrm{a}$ & $2755.3 a$ & 1 \\
\hline \multicolumn{2}{|c|}{ G3 } & $1748.7 \mathrm{~cd}$ & $1162.3 a b c$ & $3222.4 a b c$ & $3281.5 a b$ & $1929.1 \mathrm{~cd}$ & $1005.6 b c$ & $2380.6 a b c d$ & $1696.1 \mathrm{bc}$ & $3443.8 \mathrm{abc}$ & 2207.8cdef & 8 \\
\hline \multicolumn{2}{|c|}{ G11 } & $1820.2 \mathrm{~cd}$ & $1298.8 \mathrm{abc}$ & $3063.8 \mathrm{abc}$ & $3152.2 \mathrm{abc}$ & 1558.1d & $947.9 \mathrm{bc}$ & $1100.7 \mathrm{ef}$ & $1861.7 a b c$ & $3611.9 a b$ & 2046.1 ef & 14 \\
\hline \multicolumn{2}{|c|}{ G12 } & $2384.6 \mathrm{bc}$ & 1441.7abc & $2810.5 b c$ & $2579.5 \mathrm{~cd}$ & $1788.9 \mathrm{~cd}$ & $946.2 \mathrm{bc}$ & $1972.7 \mathrm{~cd}$ & $1483.6 c$ & $3014.6 \mathrm{abc}$ & 2046.9ef & 13 \\
\hline \multicolumn{2}{|c|}{$\mathrm{G} 1$} & $1499.4 \mathrm{~cd}$ & 1145.2abc & 2874.0abc & $3312.6 a b$ & $1771.8 \mathrm{~cd}$ & 1265.0abc & $1746.8 \mathrm{de}$ & $2276.9 a$ & $3111.3 a b c$ & 2111.4def & 11 \\
\hline \multicolumn{2}{|c|}{ G4 } & $2403.2 b c$ & 1386.9abc & $3519.9 a$ & 3272.2ab & 2344.9abcd & 1573.1abc & 2737.3ab & $2150.8 \mathrm{ab}$ & $3170.8 \mathrm{abc}$ & 2506.6abc & 3 \\
\hline \multicolumn{2}{|c|}{ G2 } & $1927.8 \mathrm{~cd}$ & 933.0 & $3103.6 \mathrm{abc}$ & $3265.5 \mathrm{ab}$ & $2450.5 \mathrm{abcd}$ & 1479.1abc & $2877.1 \mathrm{a}$ & $2288.5 a$ & $3192.7 \mathrm{abc}$ & $2390.9 \mathrm{bcd}$ & 4 \\
\hline \multirow{2}{*}{\multicolumn{2}{|c|}{$\begin{array}{l}\text { Env. mean } \\
\text { Overall mean }\end{array}$}} & 2081.16 & 1293.39 & 3035.282 & 3061.34 & 2240.515 & 1307.902 & 2013.759 & 1998.897 & 3201.393 & --- & \\
\hline & & & & & & & & & & & 2248.18 & \\
\hline \multirow{4}{*}{$\begin{array}{l}\text { Signific } \\
\text { ance } \\
\text { level }\end{array}$} & Env & --- & --- & --- & --- & --- & --- & --- & --- & --- & $<.0001$ & \\
\hline & Rep & 0.0044 & 0.6857 & 0.3218 & 0.5109 & 0.5632 & 0.8954 & $<.0001$ & 0.1007 & 0.2904 & 0.3631 & \\
\hline & Gen & 0.0003 & 0.1991 & 0.1770 & 0.0068 & 0.0119 & 0.0123 & $<.0001$ & 0.0357 & 0.2943 & $<.0001$ & \\
\hline & CV\% & 25.79 & 21.70 & 11.82102 & 11.41720 & 20.74911 & 28.98708 & 19.28105 & 14.65822 & 14.93192 & 22.05 & \\
\hline
\end{tabular}

Where Env = environment, Rep = replication, Gen= genotype

Genotypes:- G1= Tulu-Dimtu, G2=Farmers' cultivar, G3= Bariso, G4 = Tegegnech, G5= Agrit, G6= Latu, G7= Megeri, G8= Gume, G9= Arjo-1, G10= Seenk, G11= Wolmera, G12= Weyitu, G13= Ambericho, G14= Urji and G15= Burkitu

Environments:- E1= Bule 2011, E2= Kokate 2011, E3= Alicho-Wiriro 2011, E4= Hossaina 2012, E5= Haghere-Selam 2012, E6= Bona 2012, E7= Bule 2012, E8= Kokate 2012 and E9= Alicho-Wiriro 2012 
Table 4: AMMI adjusted mean grain yield, IPCA 1 and 2 scores, AMMI stability values (ASV) and ranking orders of 15 field pea varieties tested at 9 environments

\begin{tabular}{|c|c|c|c|c|c|c|c|}
\hline \multirow[t]{2}{*}{ Genotype and environments } & \multicolumn{2}{|c|}{ Grain Yield } & \multirow{2}{*}{$\begin{array}{l}\text { IPCA } 1 \\
\text { score }\end{array}$} & \multirow{2}{*}{$\begin{array}{l}\text { IPCA } 2 \\
\text { score }\end{array}$} & \multicolumn{2}{|c|}{ ASV } & \multirow[t]{2}{*}{ YSI } \\
\hline & $\begin{array}{c}\text { Mean } \\
\text { (Kg/ha) }\end{array}$ & $\mathrm{RY}$ & & & Value & RASV & \\
\hline Latu (G6) & 2233 & 6 & 2.3840 & 6.8581 & 8.274871 & 2 & 8 \\
\hline Burkitu (G15) & 2624 & 2 & 26.3029 & -23.1830 & 56.10099 & 14 & 16 \\
\hline Agrit (G5) & 2255 & 5 & -11.3669 & -5.6359 & 22.7854 & 11 & 16 \\
\hline Senk (10) & 2171 & 9 & 10.4732 & -0.1628 & 20.34225 & 9 & 18 \\
\hline Ambericho (G13) & 2124 & 10 & 1.5568 & 1.8390 & 3.539022 & 1 & 11 \\
\hline URJI (G14) & 2099 & 12 & -9.1992 & 7.2114 & 19.26759 & 8 & 20 \\
\hline Gume (G8) & 1937 & 15 & -27.0536 & -22.8565 & 57.30086 & 15 & 30 \\
\hline Megeri (G7) & 2755 & 1 & 12.3920 & -1.8744 & 24.14127 & 12 & 13 \\
\hline Bariso (G3) & 2208 & 8 & -2.2269 & 17.5447 & 18.06997 & 7 & 15 \\
\hline Arjo-1 (G9) & 2213 & 7 & 4.2270 & -1.7987 & 8.404631 & 3 & 10 \\
\hline Wolmera (G11) & 2046 & 14 & -11.6414 & 1.1541 & 22.63998 & 10 & 24 \\
\hline Weyitu (G12) & 2047 & 13 & 8.6313 & 1.9766 & 16.88029 & 6 & 19 \\
\hline Tullu-Dimt (G1) & 2111 & 11 & -12.9967 & 1.6650 & 25.29773 & 13 & 24 \\
\hline Tegegnech (G4) & 2507 & 3 & 5.6974 & 5.3625 & 12.29667 & 4 & 7 \\
\hline F.cultivar (G2) & 2391 & 4 & 2.8201 & 11.8999 & 13.09996 & 5 & 9 \\
\hline Genotypes mean & 2248 & & & & & & \\
\hline Bule $2011(\mathrm{E} 1)$ & 2081 & 5 & 36.8003 & -10.6348 & 72.26232 & 9 & 14 \\
\hline Kokate 2011 (E2) & 1293 & 9 & -15.9782 & -6.9397 & 31.80016 & 7 & 16 \\
\hline Alicho-Wiriro 2011 (E3) & 3035 & 3 & -2.9608 & 1.9925 & 6.086026 & 1 & 4 \\
\hline Hossaina 2012 (E4) & 3061 & 2 & -6.64519 & 1.1607 & 12.95872 & 2 & 4 \\
\hline Haghere-Selam 2012 (E5) & 2241 & 4 & 10.0891 & -11.1942 & 22.56761 & 3 & 7 \\
\hline Bona 2012(E6) & 1308 & 8 & -12.5176 & -15.9268 & 29.06463 & 6 & 14 \\
\hline Bule 2012(E7) & 2014 & 6 & 13.4267 & 25.9298 & 36.77525 & 8 & 14 \\
\hline Kokate 2012(E8) & 1999 & 7 & -12.3565 & -5.3701 & 24.59291 & 4 & 11 \\
\hline Alicho-Wiriro 2012 (E9) & 3201 & 1 & -9.8578 & 20.9827 & 28.40521 & 5 & 6 \\
\hline
\end{tabular}

IPCA1, 2 = interaction principal component axis 1 and $2, A S V=A M M I$ stability value, $Y S I$ = yield stability index, $R Y=$ the rank of the mean grain yield of genotypes, RASV =the rank of the AMMI stability

Table 5: The first four AMMI selections of genotypes for the testing environments

\begin{tabular}{|c|c|c|c|c|}
\hline \multirow[t]{2}{*}{ Environment } & \multicolumn{4}{|c|}{ Selected genotypes per location } \\
\hline & 1 & 2 & 3 & 4 \\
\hline Bule 2011 (E1) & Burkitu (G15) & Megeri (G7) & Senk (G10) & Tegegnech (G4) \\
\hline Bule 2012(E7) & F. cultivar (G2) & Megeri (G7) & Tegegnech (G4) & Latu (G6) \\
\hline Kokate 2011 (E2) & Agrit (G5) & Gume (G8) & Senk (G10) & Urii (G14) \\
\hline Kokate 2012(E8) & Megeri (Ǵ7) & Agrit (G5) & Tegegnech (G4) & Gume (G8) \\
\hline Alicho-Wiriro 2011 (E3) & Megeri (G7) & Burkitu (G15) & Tegegnech (G4) & F. cultivar (G2) \\
\hline Alicho-Wiriro 2012 (E9) & Wolmera (G11) & Bariso (G3) & Urji (G14) & Megeri (G7) \\
\hline Hossaina 2012 (E4) & Megeri (G7) & Burkitu (G15) & F. cultivar (G2) & Tegegnech (G4) \\
\hline Haghere-Selam 2012 (E5) & Burkitu (G15) & Megeri (G7) & Tegegnech (G4) & F. cultivar (G2) \\
\hline Bona 2012(E6) & Gume (G8) & Megeri (G7) & Agrit (G5) & Burkitu (G15) \\
\hline
\end{tabular}

Where F. Cultivar = Farmers' cultivar

\section{CONCLUSION}

The mean grain yields of 15 field pea genotypes across the environments ranged from $1937.2 \mathrm{~kg} / \mathrm{ha}$ for genotype G8 to $2755.3 \mathrm{~kg} / \mathrm{ha}$ for G7, followed by genotype G15 with mean grain yield of $2624.1 \mathrm{~kg} / \mathrm{ha}$. Furthermore, except five genotypes; viz. G7, G15, G4, G2 and G5, all the remaining ten genotypes performed below the grand mean in their grain yield. 
The additive main effects and multiplicative interaction (AMMI) analysis of variance for grain yield of the varieties which is combined at nine environments showed that the performance of the genotypes was highly influenced by GE interaction effects. The magnitude of the GE interaction sum of squares was more than twice larger than that of genotypes, indicating that there were differences in genotypic responses across the environments causing most of the variation in grain yield of this study. The magnitude of environment effect was more than nine times that of genotypic effect indicating the distinctness in different environments. Yield stability index (YSI) revealed that G4 and G2 are to be considered as the best genotypes in stability as well as in better yield performance above the grand mean.

\section{ACKNOWLEDGMENTS}

Southern Agricultural Research Institute (SARI) and Hawassa Agricultural Research Center (HwARC) are highly acknowledged for financial support and for supplying relevant research materials while conducting the research activities at different locations. The author is very grateful to Mrs. Woinshet Solomon and Mr.WondimagegnAmenu who were Research Technical Assistants of highland pulses and oil crops in HwARC for their uninterrupted endeavors to succeed in the research activities.

\section{REFERENCES}

Acikgoz, E., A. Ustun, I. Gul, E. Anlarsal, A. S. Tekeli, I. Nizam, et al., (2009). Genotype $x$ environment interaction and stability analysis for dry matter and seed yield in field pea (PisumsativumL.).Spanish J. of Agr. Research $7(1), 96-106$

Alake. C.O and O.J Ariyo, (2012). Comparative Analysis of Genotype x Environment Interaction Techniques in West African Okra (Abelmoschuscaillei, A. ChevStevels). J. of Agr. Sci. 4(4): 4

Anandan, A., R. Eswaran, T. Sabesan and M. Prakash, (2009).Additive main effects and multiplicative interactions analysis of yield performances in rice varieties under coastal saline environments.Adv. in Biol. Res. 3 (1-2): 4347.

Bose, L.K., N. N. Jambhulkar, K. Pande and O. N.Singh, (2014).Use of AMMI and other stability statistics in the simultaneous selection of rice genotypes for yield and stability under direct-seeded conditions. Chilean J. Agric. Res. vol.74 no.1.

Crossa, J (1990). Statistical analyses of multilocation trials. Adv. Agron. 4: 55-85

Crossa J, Gauch H G, Zobel RW (1990) Additive main effects and multiplicative interaction analysis of two international maize cultivar trials. Crop Sci 30: 493-500

Crossa, J., P.N. Fox, W.H. Pfeiffer, S. Rajaram and H.G. Gauch, (1991). AMMI adjustment for statistical analysis of an international wheat yield trial. Theor. Appl. Genet. 81: 27-37.

Debelo, D. S. Gelalcha, B. Yaie, B. Girma, B. Mamo and D. Masresha, (2004).Grain yield stability of bread wheat genotypes in favorable and stressed environments. 12th Regional Wheat Workshop for Eastern, Central and Southern Africa, pp: 76-85.

Dewi, A. K., M. A. Chozin, H. Triwidodo and H. Aswidinnoor, (2014). Genotype $\times$ environment interaction, and stability analysis in lowland rice promising genotypes. Int. J. of Agron.and Agri. Research. 5(5): 74-84

Ebdon, J.S. and H.G. Gauch (2002). Additive Main Effect and Multiplicative Interaction Analysis of National Turf grass Performance Trials: II. Cultivar Recommendations, Crop Sci. 42:497-506

Eberhart, S.A. and W.A. Russell, (1966).Stability parameters for comparing varieties.Crop. Sci. 6: 36-40

Ersullo L., Habtamu Z., and Adugna W. (2013).AMMI analysis of yields and oil content in some linseed (Linumusitatissimum L.) genotypes in south and central Ethiopia.Ethiopian J. of Agri.sci.24:79-98

Farshadfar, E., and J. Sutka.(2006). Biplot analysis of genotype-environment interaction in durum wheat using the AMMI model.ActaAgronomicaHungarica 54(4):459-467.

Fekadu G., Ersulo L., Asrat A., Fitsum A., Yeyis R. and Daniel A., (2012). GGE-Biplot analysis of grain yield of faba bean genotypes in Southern Ethiopia. Electronic j. of plant breeding, 3(3): 898-907

FetienAbay and AsmundBjornstad. (2009). Identifying optimal testing environments of barley yield in the Northern Highlands of Ethiopia by Biplot Analysis. J. of Drylands 2(1): 40-47.

FisehaBaraki, YemaneTsehay and FetienAbay, (2015).AMMI Analysis of GenotypexEnvironment Interaction and Stability of Sesame Genotypes in Northern Ethiopia.Asian J. of Plant Sciences, 13: 178-183.

Gauch, H.G. and R.W. Zobel., (1996).AMMI analysis of yield trials.In: Kang, M.S. and Gauch, S.G. (eds) Genotypicby-Environment Interaction. CRC Press, Pp. 85-121 Boca Raton, FL

Gauch H.G., (2006). Statistical analysis of yield trials by AMMI and GGE.Crop Sci. 46, 1488-1500. 
Habtamu S. and Million F., (2013).Multivariate analysis of some Ethiopian field pea (PisumsativumL.) genotypes. Int. J. of Genetics and Molecular Biology 5(6): 78-87

Hassan Z., E. Farshadfar, S. H. Sabaghpour and R. Karimizadeh, (2012). Evaluation of genotype $\times$ environment interaction in chickpea using measures of stability from AMMI model. Annals of Biological Research, 3 (7):31263136

Kaya, Y., C. Palta and S. Taner, (2002).Additive main effects and multiplicative interactions analysis of yield performance in bread wheat varieties across environments. Turk J. Agric. 26: 275-279.

Kumar, S. , D.K. Pandey, P.K. Singh and J. Singh, (2011). Genotype x environment interaction and stability analysis for sugarcane genotypes evaluated in multi-location trials.J. of Sugarcane Research 1(2) : 28-34

Makinde, S.C.O., and O.J Ariyo, (2011).Analysis of genotype $x$ environment interaction of groundnut (Arachishypogaea L.).Appl. Biol. 40(2): 19-26

Mukherjee, A.K., N. K. Mohapatra, L. K. Bose, N. N. Jambhulkar and P. Nayak, (2013). Additive main effects and multiplicative interaction (AMMI) analysis of GxE interactions in rice-blast pathosystem to identify stable resistant genotypes. Global Sci. Research J. 1(1): 103-118

Nassir A.L., O.J. Ariyo, (2011). Genotype x environment interaction and yield-stability analyses of rice grown in tropical inland swamp. Not Bot HortAgrobotCluj, 39(1):220-225

Odewale J. O., Ataga C. D., Agho C., Odiowaya G., Okoye M. N. and Okolo E. C. (2013). Genotype evaluation of coconut (Cocosnucifera $L$.) and mega environment investigation based on additive main effects and multiplicative interaction (AMMI) analysis. Res. J. of Agri. and Env. Management 2(1): 001-010

Ogunbayo, S.A., M. Sie, D.K. Ojo, A.R. Popoola, O.A. Oduwaye, I.O. Daniel, K.A. Sanni, M.G. Akinwale, B. Toulou, A. Shittu, G.B. Gregorio and E.F. Mercado, (2014). Comparative Performance of Forty-Eight Rice Genotypes in Diverse Environments Using the Ammi and GGE Biplot Analyses. Int. J. of Plant Breeding and Genetics, 8: 139152.

Purchase, J.L., (1997).Parametric stability to describe GE interactions and yield stability in winter wheat. PhD. Thesis, Faculty of Agri., Univ. of Orange Free State, Bloemfontein, South Africa.

Purchase, J.L., H. Hatting and Cs.Vandenventer. (2000). Genotype by environments interaction of wheat in South Africa: stability analysis of yield performance. South Africa J. of plant sci. 17: 101-107.

Riaz, M., M. Naveed, J. Farooq, A. Farooq, A. Mahmood, Ch. M. Rafiq, M. Nadeem and A. Sadiq, (2013). AMMI analysis for stability, adaptability and GE interaction studies in cotton (GossypiumhirsutumL.).J. of Animal \& Plant Sci, 23(3): 865-871

Romagosa, I. and P.N. Fox, (1993).Genotype x Environment interaction and Adaptation.In: Hayward, M.D. Bosemark, N.O. and Romagosa, I. (Eds.) Plant Breeding: Principles and Prospects. Chapman and Hall, London. Pp. 373-391.

Sabaghnia, N., M. Mohammadi and R. Karimizadeh, (2013).Parameters of AMMI Model for Yield Stability Analysis in Durum Wheat.Agriculturae Conspectus Scientificus . Vol. 78 (2013) No. 2 (119-124)

SAS (2000).SAS Linear Model: A Guide to ANOVA and GLM Procedures. SAS Institute Inc., Cary, NC, USA.

Tamene T.T., Gemechu K., Tadese S., Mussa J. and Yeneneh B., (2013).Genotype x environment interaction and performance stability for grain yield in field pea (Pisumsativum L.) genotypes. Int. J. of plant breeding 7(2): 116123.

Van Oosterom, E.J., D. Kleijn, S. Ceccarelli and M.M. Nachit, (1993).Genotype x Environment interactions of barley in the Mediterranean region.Crop Sci. 33: 669-74.

Yan W, and Rajcan I (2002). Biplots analysis of the test sites and trait relations of soybean in Ontario.Crop Sci. 42: $11-20$

Yayis R., Agdew B. and Yasin G., (2014). GGE and AMMI biplot analysis for field pea yield stability in SNNPR state, Ethiopia. Int. J. of Sustainable Agr. Research, 2014, 1(1): 28-38

Zobel R.W., M.J Wright, H.G Gauch. (1988). Statistical analysis of a yield trial.Agronomy J. 80: 388-393.

Cite this Article: Ersullo LJ (2016). Genotype $\times$ Environment Interaction for Grain Yield of Some Field pea Genotypes in Central and North Eastern Zones of South Region, Ethiopia. Greener Journal of Plant Breeding and Crop Science, 4(3): 071-080, http://doi.org/10.15580/GJPBCS.2016.3.050316082 